ARGENTINA ${ }^{\prime}$ :

\title{
PANDEMIA, AISLAMIENTO Y PARÁLISIS DE LA PRODUCCIÓN AUDIOVISUAL
}

DOI: https://doi.org/10.7764/obitel.21.S.3

\begin{abstract}
Autores:
Mónica Kirchheimer ${ }^{2}$ (https://orcid.org/0000-0002-3319-0520), Ezequiel Rivero ${ }^{3}$ (http://orcid.org/0000-0002-8124-0975)
\end{abstract}

\section{Introducción}

La crisis preexistente de la ficción nacional que Obitel Argentina reporta al menos desde el año 2010 se agudizó en el contexto de pandemia cuando los canales de aire estrenaron apenas cuatro títulos argentinos que representaron 61 horas y una coproducción, la cifra más baja desde que llevamos registro. Los canales líderes, en especial Telefe, obtuvieron buenos resultados de audiencia programando numerosas telenovelas de origen brasileño y turco. Si es cierto que las corporaciones mediáticas tienen todo su pasado por delante, la pandemia les permitió reponer con éxito moderado algunas ficciones que fueron sucesos en sus emisiones originales. Los datos que aquí exponemos muestran la completa parálisis de la producción nacional, un incremento abrupto e inusual de reposiciones de distinto origen, el retorno de las narco tele-

1 El equipo de Obitel Argentina agradece a Kantar Ibope Media, ya que sin la información brindada por ellos no sería posible la realización de algunos de los análisis que aquí se presentan.

2 Profesora de la Universidad Nacional de las Artes (UNA) y de la Universidad Nacional de Buenos Aires.

3 Becario Conicet en la Universidad Nacional de Quilmes (UNQ). 
novelas a la TV abierta y el rol destacado de la Televisión Pública en la emisión de un número significativo de títulos nacionales, algunos estrenos, y especialmente reposiciones (Nicolosi, 2021) que permitieron a los actores el cobro de las regalías por derechos de intérprete, un dato relevante en un contexto crítico y de virtual parálisis para la industria de la ficción en su conjunto.

\section{El Contexto Audiovisual de Argentina en 2020}

Marcado por el impacto de la crisis sanitaria, el contexto audiovisual en 2020 arroja un saldo negativo en casi todas sus áreas. En relación al impacto de la Covid-19 en la producción de Valor Agregado Bruto (VAB), es decir su contribución a la creación de riqueza, la generación y sostenimiento de empleos y el consumo, los indicadores son, como es de esperar, a la baja. La actividad audiovisual más afectada fue la exhibición cinematográfica en salas que tuvo la menor cantidad de entradas vendidas desde que existen registros y, posiblemente, la menor cantidad en un siglo (INCAA, 2020). El impedimento de la presencialidad y aglomeración de personas en espacios cerrados incluyeron a esta actividad entre las primeras en cerrarse como parte de las medidas de contención promovidas por el gobierno nacional a partir del día 19 de marzo de 2020. A su vez, las numerosas limitaciones y acotado aforo permitido en el regreso de la actividad durante el último tramo del año no permitieron una recuperación de la actividad, aunque sí el reinicio de la revinculación con los públicos. La televisión fue considerada una actividad esencial y sus trabajadores exceptuados de las restricciones de circulación que regían para el resto de la población (Decreto 297/2020 art. 6to, inciso 9) por lo que los niveles de actividad de la emisión se mantuvieron, aunque no en el ámbito específico de la ficción que fue paralizada. A su vez, y pese a la recesión económica que acompañó la pandemia, los niveles de suscripción a la televisión de pago de mantuvieron. Esto obedece, en parte, a los cambios en la domesticidad y rutinas de las personas que dispusieron inicialmente 
de mayor tiempo para el ocio y el consumo de bienes culturales en el hogar (SInCA, 2020). En la televisión abierta, se destaca la mayor presencia de contenidos informativos, la continuidad de la tendencia a la baja de la audiencia y una drástica reducción de las horas de estreno de ficción debido a la parálisis de los rodajes, por lo que la programación se sostuvo mayormente en reposiciones y contenidos de entretenimiento.

\subsection{La televisión abierta en Argentina}

De las industrias culturales, la industria audiovisual es la de mayor magnitud económica: aporta el $84 \%$ del valor agregado bruto del sector cultural y el 51,2\% de los empleos (Bulloni Yaquinta et al., 2021). La televisión abierta en particular realiza un aporte significativo y durante 2020 no estuvo exento de dificultades generadas, en parte, por la contracción del mercado publicitario. No obstante, las principales emisoras que se analizan en este capítulo no manifestaron mayores alteraciones y continuaron sus operaciones en medio de la atipicidad del contexto.

El sistema de televisión abierta en Argentina está conformado por seis cadenas con cobertura nacional. La TV Pública forma parte del Sistema Federal de Medios y Contenidos Públicos y se financia con aportes del Tesoro Nacional, publicidad oficial, gravámenes previstos por la Ley de Servicios de Comunicación Audiovisual y otros recursos propios. Las otras cinco cadenas son de gestión comercial privada.

\section{Cuadro 1. Cadenas nacionales de televisión abierta en Argentina}

\begin{tabular}{|c|c|}
\hline Cadenas privadas (5) & Cadenas públicas (1) \\
\hline América 2 (canal 2) & TV Pública (canal 7) \\
\hline El Nueve (canal 9) & \\
\hline Telefe (canal 11) & \\
\hline El Trece (canal 13) & \\
\hline Net TV & \\
\hline \multicolumn{2}{|c|}{ TOTAL CADENAS = 6 }
\end{tabular}

Fuente: Obitel Argentina 
Las cuatro cadenas tradicionales llegan a todo el país a través de filiales, repetidoras o venta de contenidos: TV Pública, Telefe, El Trece y El Nueve. Aunque con niveles marginales de audiencia, funciona desde 2018 la cadena de aire del Grupo Perfil, Net TV, con una programación generalista. En algunas franjas horarias esta nueva señal disputa la sexta posición a una muy debilitada TV Pública. Solo la emisora estatal posee licencia nacional y cubre con su señal la mayor parte del territorio nacional $(99,5 \%)$, mientras que los líderes, Telefe y E1 Trece, llegan a todas las provincias a través de la propiedad directa o por asociación con las principales emisoras locales. Las seis cadenas de alcance nacional emiten su programación a través de la televisión por cable, mayoritariamente de gestión privada y con alta penetración en el país. La TV Pública depende formalmente del directorio de Radio y Televisión Argentina Sociedad del Estado (RTA S.E.), que funciona en el ámbito del Sistema Federal de Medios y Contenidos Públicos (SFMyCP), creado en 2015. América forma parte del grupo América Medios. Telefe es propiedad de la estadounidense Viacom Inc., junto con ocho repetidoras del interior del país. El holding Clarín explota El Trece a través de su división Artear y es propietario de radios, diarios, canales abiertos, y las empresas de TV de pago y banda ancha fija más importantes del país. También es copropietario de la única fábrica de papel para prensa. La propiedad de El Nueve es objeto de litigio judicial, entre el presidente del Directorio, el empresario local Carlos Loréfice Lynch y el inversor mexicano Remigio González González. El trámite legal que sigue su curso en un tribunal de Delaware (Estados Unidos) no impidió la venta del 90\% del paquete accionario al Grupo Octubre a cargo de Víctor Santa María, un sindicalista devenido empresario de medios. Grupo Octubre se ha expandido los últimos años en el negocio de la prensa gráfica con la compra del diario Página/12 y varias revistas; la radiofonía a través de la posesión de una de las AM más escuchadas en Buenos Aires (AM 
750) y numerosas radios FM. Sobre fines de 2020 creó también una señal de noticias para televisión de pago, IP.

\section{Gráfico 1. Audiencia y share por emisora}

\begin{tabular}{|l|c|c|c|}
\hline Emisora & $\begin{array}{l}\text { Rating } \\
\text { Hogares }\end{array}$ & \% & $\begin{array}{c}\text { Share } \\
(\%)\end{array}$ \\
\hline Telefe & 7,8 & 40,9 & 18,3 \\
\hline El Trece & 5,8 & 30,6 & 13,7 \\
\hline América & 2,0 & 10,7 & 4,8 \\
\hline El Nueve & 2,3 & 12,2 & 5,5 \\
\hline TV Pública & 0,6 & 3,2 & 1,5 \\
\hline Net TV & 0,4 & 2,3 & 1,0 \\
\hline TOTAL & 19,0 & 100 & 44,8 \\
\hline
\end{tabular}

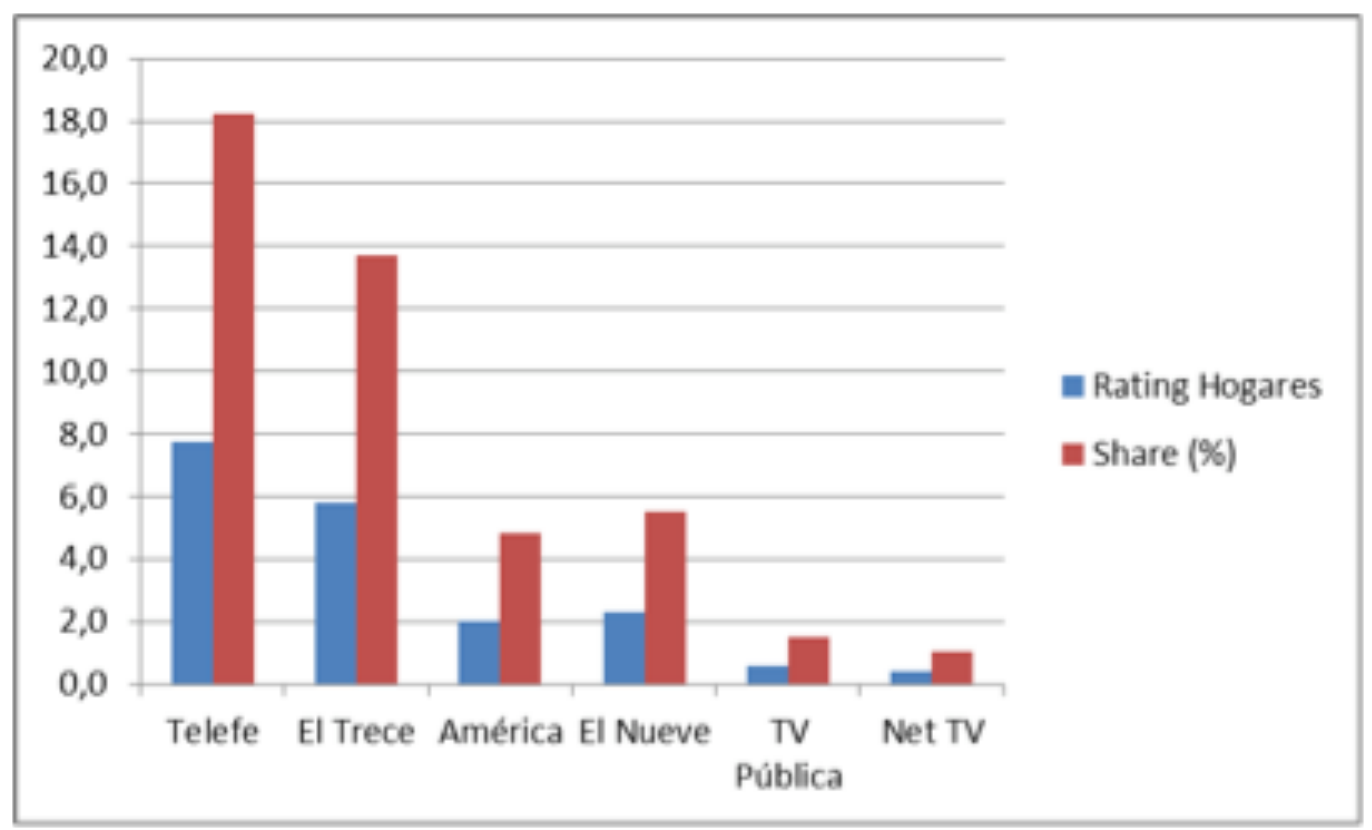

Fuente: Kantar Ibope Media y Obitel Argentina 
Gráfico 2. Géneros y horas transmitidos en la programación de TV

\begin{tabular}{|l|c|c|}
\hline $\begin{array}{l}\text { Géneros } \\
\text { Transmitidos }\end{array}$ & $\begin{array}{c}\text { Horas de } \\
\text { exhibición }\end{array}$ & $\%$ \\
\hline Información & $12.008: 00$ & 24,3 \\
\hline Ficción & $7.047: 00$ & 14,3 \\
\hline Entretenimiento & $7.425: 00$ & 15,1 \\
\hline Religioso & $1.349: 00$ & 2,7 \\
\hline Deporte & $1.065: 00$ & 2,2 \\
\hline Educativo & $1.668: 00$ & 3,4 \\
\hline Infantil & $1.884: 00$ & 3,8 \\
\hline Otros & $16.887: 00$ & 34,2 \\
\hline TOTAL & 49.333 & 100 \\
\hline
\end{tabular}

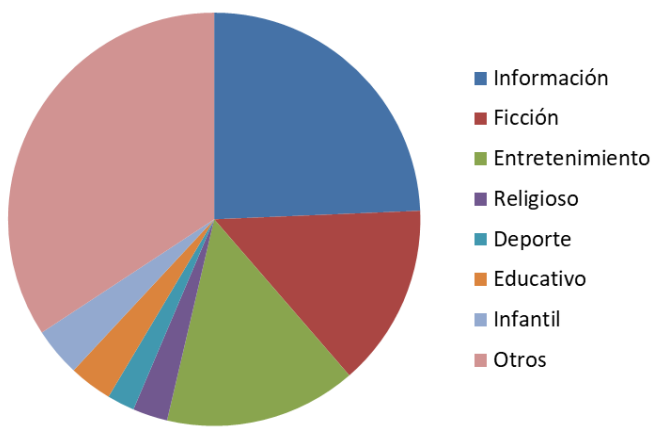

Fuente: Kantar Ibope Media y Obitel Argentina

En 2020 se observa un incremento en la oferta de contenidos informativos por la excepcionalidad de los hechos vinculados a la pandemia y la mayor avidez de las audiencias en acceder en vivo, especialmente a las decisiones oficiales durante los meses de marzo y abril. Este periodo es también coincidente con un incremento significativo en el rating de todas las señales de noticias que se transmiten a través de la televisión de pago (Espada, 2020; Kantar-Ibope Media, 2021). A su vez, se observa una caída notable en la cantidad de horas dedicadas al deporte, en parte por la falta de actividades en este rubro durante buena parte del año. Cayeron además dos géneros largamente descuidados por la televisión abierta como el humor y los contenidos infantiles. Esto último resulta paradojal, en la medida en que, como señalan consultoras como Parrot Analytics (2020), el año estuvo marcado por un giro hacia una mayor demanda de contenidos alegres, pasatistas y destinados al público infanto-juvenil, esto último por la mayor presencia de estas audiencias dentro de los hogares. En este punto, la televisión abierta parece haber resignado la posibilidad de concentrar audiencias más jóvenes desde la pantalla lineal (y ello a pesar de que la Televisión Pública ofreció una serie educativa diaria de cuatro horas de duración ${ }^{4}$ ).

4 Se trata del programa Seguimos Educando, una iniciativa conjunta de la Televisión Pública y el Ministerio de Educación de la Nación, que distribuyó un promedio de siete horas 
La ficción pasó del 7,4\% en 2019 al 14\% del total de las horas emitidas en 2020, aunque una porción mínima de ese total se trata de ficción nacional de estreno.

La audiencia de la televisión abierta siguió su tendencia decreciente que lleva una larga década de migración de públicos a otras plataformas. Con la única excepción de Telefe, los demás canales abierto continuaron perdiendo audiencia, pese a la excepcionalidad del año, la mayor disponibilidad de tiempo para el entretenimiento y la mayor demanda de contenidos informativos. En conjunto los cinco canales de aire capturan el 44,8\% del share de la televisión lineal, exactamente un punto menos que el año anterior, siendo superada por el conjunto de las señales de televisión de pago, que ya alcanzan una cuota del 55,2\% del share televisivo total.

Telefe amplía su ventaja como líder sobre El Trece, que permanece en segundo lugar. La Televisión Pública no consigue romper con un ciclo de pérdida de audiencia que Obitel Argentina reporta desde 2016, y durante 2020 cayó en un 40\% en relación al año anterior, promediando apenas 0,6 puntos, debajo incluso de muchas señales de televisión de pago.

\subsection{La TV de pago y plataformas VoD en Argentina}

Según datos del Ente Nacional de Comunicaciones (ENaCom) para el tercer trimestre de $2020^{5}$, el 69,3\% de los hogares argentinos contaba con algún servicio de televisión de pago, mayoritariamente mediante vínculo físico, mientras que la tecnología satelital captura una cuota menor del mercado que no llega al 20\%. Si se suman las conexiones clandestinas se estima que cerca del $80 \%$ de los hogares del país tendrían acceso a este servicio, uno de los niveles de penetración más altos del continente. Son 7,3 millones de hogares los que cuentan 
con este servicio, un incremento marginal en relación a los reportados el año anterior. No obstante, según informa el mismo ente oficial, existen importantes asimetrías geográficas en el acceso al servicio: mientras provincias como Córdoba, Tierra de Fuego, La Pampa y Ciudad Autónoma de Buenos Aires exhiben cifras por encima del $60 \%$, en el otro extremo Catamarca, Tucumán, La Rioja, entre otras, rondan el 25\%. El mercado de la TV paga se encuentra fuertemente concentrado principalmente en Cablevisión, una división del Grupo Clarín, que controla el $40 \%$ del mercado, especialmente en capitales de provincias y los centros urbanos más rentables. Existen además actores periféricos como cooperativas de telecomunicaciones y PyMEs que prestan este servicio en lugares más alejados de los grandes centros urbanos y de menor densidad poblacional e interés comercial, los que conjuntamente manejan menos del 20\% del mercado de TV por suscripción. La tendencia que Obitel Argentina ha reportado los últimos años referida a las alianzas entre cadenas de televisión de pago, operadores y canales de TV abierta para la producción y distribución de ficciones en distintas plataformas también se vio afectada por la parálisis generalizada del sector.

\section{Cuadro 2. Cadenas de televisión de pago en Argentina}

\begin{tabular}{|l|}
\hline $\begin{array}{c}\text { Cadenas de TV Pago destacadas } \\
\text { en } 2020\end{array}$ \\
\hline A24 (informativo - Argentina) \\
TN (informativo - Argentina) \\
C5N (informativo - Argentina) \\
LN+ (informativo - Argentina) \\
Crónica TV (informativo - \\
Argentina) \\
Canal 26 (informativo - Argentina) \\
CNN Español (informativo - \\
Estados Unidos) \\
IP (informativo - Argentina) \\
\hline TOTAL: 8 cadenas informativas \\
\hline
\end{tabular}

Fuente: Obitel Argentina 
El mercado de la televisión de pago en Argentina tiene la particularidad de ofrecer una profusa y creciente cantidad de cadenas nacionales dedicadas a la emisión de contenidos informativos, de opinión y debate político. A 2020 se registraban 7 cadenas de capitales nacionales junto a $\mathrm{CNN}$ en español que produce algunos ciclos conducidos por periodistas argentinos. Estas emisoras se ubican habitualmente entre las más vistas de las señales de TV de pago y en las franjas del primetime llegan a superar a Net TV, la TV Pública, América y El Nueve. En efecto, durante 2020 en conjunto sumaron un promedio de 8,2 puntos de rating, más que el canal líder de televisión abierta. Hacia fines de año, se sumó una nueva estación a la grilla, IP, la señal informativa del Grupo Octubre controlante de Canal 9. Durante este año no se registró el estreno de ficción nacional en ningún canal de televisión por suscripción.

\section{Cuadro 3. El VoD en Argentina}

\begin{tabular}{|l|l|}
\hline \multicolumn{1}{|c|}{$\begin{array}{c}\text { 10 Principales plataformas de } \\
\text { VoD activas en 2020 }\end{array}$} & Total \\
\hline $\begin{array}{l}\text { Netflix; Prime Video (Amazon); } \\
\text { Movistar Play (Telefónica); Claro } \\
\text { Video (América Móvil); Disney+; } \\
\text { HBO Go (Warner Media); } \\
\text { Cablevisión Flow (Telecom); } \\
\text { Cine.ar Play y Cont.ar (Estado } \\
\text { Nacional); Sensa (Colsecor) }\end{array}$ & $\mathbf{1 0}$ \\
\hline TOTAL & $\mathbf{1 0}$ \\
\hline
\end{tabular}

Fuente: Obitel Argentina.

El cuadro anterior presenta un listado de las 10 principales plataformas de video a demanda activas en Argentina a 2020. No se trata de un listado exhaustivo sino apenas una muestra de actores con mayor penetración de mercado (Netflix, Cablevisión Flow) junto a 
otros que aportan diversidad de propiedad como es el caso de Sensa (una plataforma de VOD cooperativa) o las que pertenecen al Estado Nacional. No se incluyen a los fines de este listado los canales oficiales en YouTube de las emisoras de televisión abierta.

\subsection{Productoras independientes de ficción televisiva}

Tres canales de televisión abierta exhibieron ficción nacional de estreno durante 2020: El Trece, Telefe y la TV Pública. En el primer caso se trató de la ficción Separadas una producción de Pol-Ka cuya emisión fue primero suspendida ante la imposibilidad de continuar los rodajes y más tarde cancelada definitivamente en medio de entredichos públicos y desavenencias entre la casa productora, algunas de sus protagonistas y la Asociación Argentina de Actores. Desde ese momento Pol-Ka, una de las mayores productoras independientes de ficción del país, inició un proceso de retracción que incluyó la reducción de su planta de trabajadores y dificultades para pagar sueldos, que fueron cubiertos parcialmente con ayudas de emergencia provistas por el Estado Nacional. Telefe presentó Los Internacionales, una miniserie de ocho episodios coproducida junto a Colombia, con la participación de Viacom International Studios, mientras que la TV Pública emitió la primera ficción producida en pandemia, Terapia en Cuarentena, una miniserie de NOS producciones con escasa experiencia previa en ficción.

\subsection{Fuentes de financiamiento del sector audiovisual}

La Cámara Argentina de Medios (CAAM), informa que "la pandemia hizo que el 2020 sea un año muy particular en cuanto al consumo de medios. En millones de USD, en 2019 la inversión publicitaria total estimada fue de USD 1.016 y en 2020 cayó a USD 703”. 


\section{Gráfico 3. Inversión Publicitaria estimada en la industria (en millones USD)}

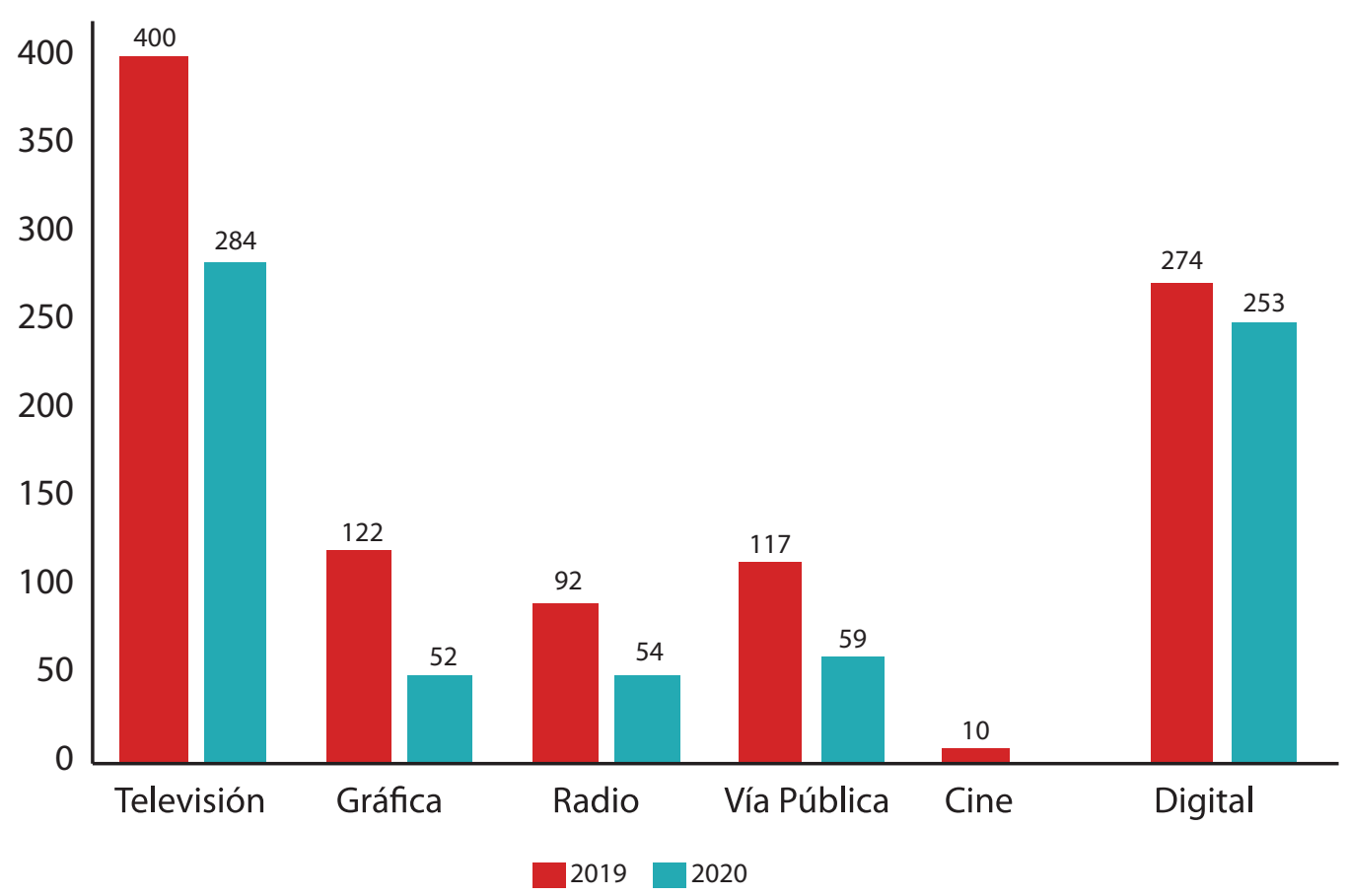

Fuente: Cámara Argentina de Agencia de Medios

De acuerdo con sus estimaciones la caída global fue de algo más del $30 \%$ en relación con el 2019, la mayor caída se evidencia en la inversión en televisión y desaparece completamente para el cine. Aunque la televisión domina el reparto de la torta publicitaria, pierde terreno año a año frente a Internet, que a 2019 concentraba el 27\% de la inversión. La televisión resulta en cambio más beneficiada proporcionalmente por la pauta estatal. Según datos oficiales para el segundo semestre de 2020 los seis canales de televisión abierta recibieron $\$ 843.485 .211$ millones de pesos argentinos, lo que representa el 17\% de la inversión total realizada por el Estado Nacional en ese periodo7. Según datos de ENaCom durante el tercer trimestre de 2020 los Servicios de

7 Datos oficiales de Jefatura de Gabinete de Ministros para el segundo semestre de 2020. Disponible en https://www.argentina.gob.ar/sites/default/files/informe_publicidad_oficial_2020_2.pdf 
Comunicación Audiovisual, rubro que concentra televisión y radio, tuvieron una facturación de \$25.718 millones de pesos argentinos, lo que representa el $5 \%$ de la facturación total del sector de la información y la comunicación en el país. La televisión por suscripción era un negocio ampliamente más lucrativo y en el mismo periodo obtuvo ingresos por \$ 112.404 millones. El fondo de fomento que administra el instituto de cine (INCAA) es otra fuente de financiación para la realización de películas y series de ficción, pero en 2020 se limitó a ejecuciones presupuestarias mínimas. Por otra parte, ese fondo se compone en su mayor parte de un gravamen que se carga sobre las entradas de cine por lo que la falta de concurrencia de las personas a las salas afectó severamente los recursos disponibles para financiar nuevos contenidos.

\subsection{Políticas de comunicación}

En 2020, la situación inédita que generó la pandemia de la Covid-19 expuso con mayor claridad una serie de exclusiones y desigualdades digitales que tuvieron como centro la cuestión de la conectividad y sus asimetrías. Ante una mayor demanda de conectividad para la educación, el trabajo, las compras, trámites bancarios o estatales, el entretenimiento y la información, estas desigualdades previas se profundizaron, dejando a buena parte de la ciudadanía en una situación de mayor carencia relativa respecto del momento anterior a la pandemia, cuestión que el Estado Nacional abordó con diferentes herramientas de política pública. Entre las diferentes acciones puntuales orientadas a facilitar el acceso a dispositivos y conectividad especialmente en zonas más vulnerables y barrios populares, se destaca el Decreto de Necesidad y Urgencia 690 de agosto de 2020 que declara servicio público a la telefonía móvil, reestablece la figura de "servicios públicos en competencia" a los servicios de Tecnologías de la Información (telefonía, internet, TV paga) y suspende los aumentos de sus tarifas hasta fin de año. Al cierre de este capítulo aspectos de la reglamentación del Decre- 
to, especialmente los referidos a la intervención estatal en la regulación de las tarifas de los servicios ahora declarados públicos, se encontraba judicializada, parcialmente cumplida por solo algunas empresas, en especial cooperativas que decidieron su acatamiento.

\subsection{Infraestructura de conectividad digital y móvil}

La telefonía móvil sigue siendo junto con la televisión abierta y gratuita, la tecnología de acceso a la información más extendida con una penetración a nivel nacional que supera el 100\% en casi todas las regiones del país, y un promedio nacional del 120,1\% según datos de ENaCom para el tercer trimestre de 2020. No obstante, más del 50\% de las líneas móviles activas son prepagas, habitualmente de uso más extendido entre los sectores de nivel socioeconómico medio bajo. El despliegue de la tecnología 4G ha crecido de manera acelerada en los últimos años alcanzando una amplia cobertura del territorio. Durante 2020, la instalación de la infraestructura necesaria para llevar el servicio a distintos puntos del país se ralentizó, pero no se detuvo. No obstante, al tercer trimestre de 2020, 15 departamentos de 9 provincias no contaban con este tipo de servicio.

Con relación a la banda ancha al hogar, la penetración promedio a nivel nacional alcanza al 66,3\% de los hogares del país, un leve incremento respecto de 2019, probablemente motivado en la mayor cantidad de actividades que pasaron a requerir acceso a internet en el hogar desde el inicio de la cuarentena. Asimismo, se observan regiones como la Ciudad de Buenos Aires donde la adopción del servicio es casi total, y otras provincias como Formosa, Mendoza, San Juan y Santa Cruz, donde esta cifra no supera el $40 \%$ de los hogares. Aunque la velocidad media nacional supera los $40 \mathrm{Mbps}$ de descarga (casi el doble que el año anterior) y son comunes las ofertas de acceso a más de $+30 \mathrm{Mbps}$, el 31\% de las conexiones domésticas se concentra en el rango de velocidad que va desde 1 a $6 \mathrm{Mbps}$, con grandes variaciones en la velocidad disponibles según la provincia. La fibra óptica, una de 
las tecnologías más robustas y con mejores capacidades para soportar la transmisión de grandes cantidades de datos como los que demanda el VoD, representa el 8,3\% de los accesos, casi dos puntos más que el año anterior ${ }^{8}$.

La extensión territorial sumada a la dispersión de la población en ámbitos rurales o en pequeñas concentraciones urbanas, se combina con la ausencia o baja calidad de la infraestructura de conectividad en algunas regiones y las dificultades económicas, que impiden el acceso a internet. La ausencia del mercado y del estado en algunas zonas del país ha permitido el despliegue de la actividad de cooperativas de telecomunicaciones, y de forma más experimental la emergencia de redes comunitarias de acceso a internet autogestionadas por los propios pobladores.

\section{Análisis del Año: la Ficción de Estreno Nacional e Iberoamerica- na en la TV abierta}

Tabla 1. Ficciones exhibidas en $\mathbf{2 0 2 0}$

\begin{tabular}{|c|c|}
\hline TÍTULOS INÉDITOS NACIONALES - 4 & TÍTULOS REPOSICIONES- 30 \\
\hline $\begin{array}{l}\text { EI Trece - } \mathbf{1} \text { título nacional } \\
\text { 1. Separadas (telenovela) } \\
\text { TV Pública - } \mathbf{3} \text { títulos nacionales } \\
\text { 2. La Persuasión (serie) } \\
\text { 3. Si solo si } 3 \text { (miniserie) } \\
\text { 4. Terapia en cuarentena (miniserie) } \\
\text { Telefe - 0 } \\
\text { Canal } 9 \text { - } 0 \\
\text { América - } 0 \\
\text { Net TV - 0 } \\
\text { COPRODUCCIONES - } 1 \\
\text { Telefe - } 1 \text { título } \\
\text { Los Internacionales (Argentina / Colombia) }\end{array}$ & $\begin{array}{l}\text { Telefe }-\mathbf{3} \text { títulos } \\
\text { 1. Casados con hijos (serie - Argentina) } \\
\text { 2. Elif (telenovela -Turquía) } \\
\text { 3. Floricienta (telenovela - Argentina) } \\
\text { 4. Perra vida (serie-Brasil) } \\
\text { El Trece - } \mathbf{4} \text { títulos } \\
\text { 5. Argentina tierra de amor y venganza (telenovela - } \\
\text { Argentina) } \\
6 . \quad \text { El tigre Verón (serie - Argentina) } \\
\text { 7. Las mil y una noches (telenovela - Turquía) } \\
\text { 8. Otros pecados (miniserie - Argentina) } \\
\text { Net TV - } 8 \text { títulos } \\
\text { 9. El cartel (telenovela - Colombia) } \\
\text { 10. El patrón del mal (telenovela - Colombia) } \\
\text { 11. La niña (telenovela - Colombia) } \\
\text { 12. La reina del flow (telenovela - Colombia) } \\
\text { 13. La ruta blanca (telenovela - Colombia/México) } \\
\text { 14. La viuda negra (telenovela - Colombia) } \\
\text { 15. Las muñecas de la mafia (telenovela - Colombia) } \\
\text { 16. Tiro de gracia (telenovela - Colombia) }\end{array}$ \\
\hline
\end{tabular}

8 Son datos oficiales de ENaCom. Disponible en https://indicadores.enacom.gob.ar/ Informes 


\begin{tabular}{|c|c|}
\hline $\begin{array}{l}\text { TÍTULOS IMPORTADOS INÉDITOS } \\
\text { OBITEL }-7\end{array}$ & TÍTULOS REPOSICIONES- 30 \\
\hline $\begin{array}{l}\text { Telefe - } \mathbf{3} \text { títulos } \\
\text { 1. Acoso (miniserie - Brasil) } \\
\text { 2. Club } 57 \text { (telenovela- Italia/USA hispano) } \\
\text { 3. Jesús (telenovela - Brasil) } \\
\text { Net TV - } \mathbf{3} \text { títulos } \\
\text { 4. Fugitivos (serie - Colombia) } \\
\text { 5. La ley secreta (serie - Colombia) } \\
\text { 6. La promesa (serie - Colombia) } \\
\text { TV Pública - } 1 \text { título } \\
\text { 7. La otra mirada (serie - España) }\end{array}$ & $\begin{array}{l}\text { TV Pública - } \mathbf{1 4} \text { títulos } \\
\text { 17. Amores de historia (miniserie - Argentina) } \\
\text { 18. Balas perdidas (miniserie - Argentina) } \\
\text { 19. Conflictos modernos (miniserie - Argentina) } \\
\text { 20. Doce casas (miniserie - Argentina) } \\
\text { 21. El secretario (miniserie - Argentina) } \\
\text { 22. En terapia (miniserie - Argentina) } \\
\text { 23. Germán últimas viñetas (miniserie - Argentina) } \\
\text { 24. Historia de un clan (miniserie - Argentina) } \\
\text { 25. Jorge (miniserie - Argentina) } \\
\text { 26. La última hora (miniserie - Argentina) } \\
\text { 27. Las } 13 \text { esposas de Wilson Fernández (miniserie - } \\
\text { Argentina) } \\
\text { 28. Los Sónicos (miniserie - Argentina) } \\
\text { 29. Ultimátum (miniserie - Argentina) } \\
\text { 30. Variaciones Walsh (miniserie - Argentina) } \\
\text { TOTAL GRAL. INÉDITOS } \\
\text { NACIONALES: 5 } \\
\text { TOTAL GRAL. INÉDITOS OBITEL: } 7 \\
\text { TOTAL DE TÍTULOS INÉDITOS } \\
\text { (NACIONAL Y OBITEL):12 }\end{array}$ \\
\hline
\end{tabular}

*Durante 2020 Telefe emitió siete telenovelas turcas: Alas rotas, Cesur, Fuerza de mujer, Guerra de rosas, Huérfanas, Lazos de Sangre, Y tu quien eres Fuente: Kantar Ibope Media y Obitel Argentina

En 2020 se estrenaron 11 títulos del ámbito Obitel, contra 26 del año anterior. Esto consolida una tendencia decreciente que se inició en 2014 cuando los estrenos alcanzaron los 48 títulos. El Trece puso al aire los primeros capítulos de una telenovela, Separadas, cuyas grabaciones fueron primero suspendidas producto de la pandemia y luego cancelada definitivamente. Telefe programó cerca de trasnoche una miniserie argentina-colombiana, Los Internacionales, en la que participó como productora su controlante Viacom International Studios, aunque con magros resultados en materia de audiencia. Finalmente, la TV Pública presentó de forma inédita para la televisión abierta tres miniseries, dos de las cuales se encontraban finalizadas al momento del inicio de la cuarentena y una tercera que se convirtió en la primera ficción filmada en confinamiento. Se destacan la persistencia de las 
telenovelas brasileñas que emite principalmente Telefe, junto a la novedad de Net TV que intensificó su perfil ficcional de la mano de narco telenovelas de origen colombiano.

Tabla 2: La Ficción de Estreno en 2020: países de origen

\begin{tabular}{|l|c|c|c|c|c|c|}
\hline \multicolumn{1}{|c|}{ País } & Títulos & $\mathbf{\%}$ & $\begin{array}{c}\text { Capítulos/ } \\
\text { Episodios }\end{array}$ & $\mathbf{\%}$ & Horas & $\%$ \\
\hline NACIONAL (total) & $\mathbf{5}$ & $\mathbf{4 1 , 7}$ & $\mathbf{8 3}$ & $\mathbf{1 7 , 5}$ & $\mathbf{6 1 : 4 5}$ & $\mathbf{1 4 , 7}$ \\
\hline PAÍSES OBITEL (total) & $\mathbf{7}$ & $\mathbf{5 8 , 3}$ & $\mathbf{3 9 2}$ & $\mathbf{8 2 , 5}$ & $\mathbf{3 5 6 : 1 5}$ & $\mathbf{8 5 , 3}$ \\
\hline Argentina & 4 & 33,3 & 75 & 15,8 & $55: 00$ & 13,2 \\
\hline Brasil & 2 & 16,7 & 136 & 28,6 & $179: 00$ & 42,9 \\
\hline Chile & 0 & 0,0 & 0 & 0,0 & $0: 00$ & 0,0 \\
\hline Colombia & 3 & 25,0 & 194 & 40,8 & $153: 00$ & 36,7 \\
\hline Ecuador & 0 & 0,0 & 0 & 0,0 & $0: 00$ & 0,0 \\
\hline España & 1 & 8,3 & 2 & 0,4 & $01: 25$ & 0,3 \\
\hline EEUU (producción hispánica) & 1 & 8,3 & 60 & 12,6 & $22: 50$ & 5,4 \\
\hline México & 0 & 0,0 & 0 & 0,0 & $0: 00$ & 0,0 \\
\hline Perú & 0 & 0,0 & 0 & 0,0 & $0: 00$ & 0,0 \\
\hline Portugal & 0 & 0,0 & 0 & 0,0 & $0: 00$ & 0,0 \\
\hline Uruguay & 0 & 0,0 & 0 & 0,0 & $0: 00$ & 0,0 \\
\hline Venezuela & 0 & 0,0 & 0 & 0,0 & $0: 00$ & 0,0 \\
\hline COPRODUCIONES (total) & $\mathbf{0}$ & $\mathbf{0 , 0}$ & $\mathbf{0}$ & $\mathbf{0 , 0}$ & $\mathbf{0 : 0 0}$ & $\mathbf{0 , 0}$ \\
\hline Coproducciones argentinas & $\mathbf{1}$ & $\mathbf{0 , 0}$ & $\mathbf{8}$ & $\mathbf{0 , 0}$ & $\mathbf{0 6 : 4 5}$ & $\mathbf{0 , 0}$ \\
\hline $\begin{array}{l}\text { Coproducciones entre países } \\
\text { Obitel }\end{array}$ & $\mathbf{0}$ & $\mathbf{0 , 0}$ & $\mathbf{0}$ & $\mathbf{0 , 0}$ & $\mathbf{0 : 0 0}$ & $\mathbf{0 , 0}$ \\
\hline TOTAL GENERAL & $\mathbf{1 2}$ & $\mathbf{1 0 0 , 0}$ & $\mathbf{4 7 5}$ & $\mathbf{0 , 0}$ & $\mathbf{4 1 8 : 0 0}$ & $\mathbf{1 0 0 , 0}$ \\
\hline
\end{tabular}

Fuente: KantarIbope Media y Obitel Argentina

En cuanto a la ficción de estreno nacional, se registra una caída general en todos los indicadores observados en comparación con el año anterior. En 2019 los títulos de estreno nacional fueron 18, contra 5 de 2020; la cantidad de episodios cayó de 480 a 83 y las horas de 371 a 61. Sin embargo, la ficción de estreno del ámbito Obitel registró una caída mucho más leve y logró conservar su lugar en la pantalla local: pasó de 8 títulos en 2019 a 7 en 2020; de 421 episodios a 392 y de 293 horas a 356 el último año. 
TABLA 3. Formatos de la ficción nacional e iberoamericana

\begin{tabular}{|l|c|c|c|c|c|c|c|c|c|c|c|c|}
\hline \multirow{2}{*}{ Formato } & \multicolumn{9}{|c|}{ Nacionales } & \multicolumn{5}{|c|}{ Ibero-americanos } \\
\cline { 2 - 14 } & Títulos & $\mathbf{\%}$ & $\mathbf{C} / \mathbf{E}$ & $\mathbf{\%}$ & $\mathbf{H}$ & $\mathbf{\%}$ & Títulos & $\mathbf{\%}$ & $\mathbf{C} / \mathbf{E}$ & $\mathbf{\%}$ & $\mathbf{H}$ & $\mathbf{\%}$ \\
\hline Telenovela & 1 & 20,0 & 35 & 42,2 & $35: 00$ & 56,9 & 3 & 42,8 & 194 & 49,5 & $210: 30$ & 59,0 \\
\hline Serie & 0 & 0,0 & 0 & 0,0 & $00: 00$ & 0,0 & 3 & 42,8 & 190 & 48,5 & $140: 45$ & 39,4 \\
\hline Miniserie & 4 & 80,0 & 48 & 57,8 & $26: 45$ & 43,1 & 1 & 14,4 & 8 & 2,0 & $05: 40$ & 1,6 \\
\hline Telefilme & 0 & 0,0 & 0 & 0,0 & $0: 00$ & 0,0 & 0 & 0,0 & 0 & 0,0 & $0: 00$ & 0,0 \\
\hline Unitario & 0 & 0,0 & 0 & 0,0 & $0: 00$ & 0,0 & 0 & 0,0 & 0 & 0,0 & $0: 00$ & 0,0 \\
\hline Docudrama & 0 & 0,0 & 0 & 0,0 & $0: 00$ & 0,0 & 0 & 0,0 & 0 & 0,0 & $0: 00$ & 0,0 \\
\hline Otros & 0 & 0,0 & 0 & 0,0 & $0: 00$ & 0,0 & 0 & 0,0 & 0 & 0,0 & $0: 00$ & 0,0 \\
\hline Total & $\mathbf{5}$ & $\mathbf{1 0 0 , 0}$ & $\mathbf{8 3}$ & $\mathbf{1 0 0 , 0}$ & $\mathbf{6 1 : 4 5}$ & $\mathbf{1 0 0 , 0}$ & $\mathbf{7}$ & $\mathbf{1 0 0 , 0}$ & $\mathbf{3 9 2}$ & $\mathbf{1 0 0 , 0}$ & $\mathbf{3 5 6 : 1 5}$ & $\mathbf{1 0 0 , 0}$ \\
\hline
\end{tabular}

* se incluyen en el cálculo nacional los títulos de coproducción

Fuente: Kantar Ibope Media y Obitel Argentina

Si se considera la cantidad de títulos nacionales de estreno, una vez más y al igual que el año anterior se impone la miniserie sobre los demás formatos. La telenovela, por su parte, es primera en cantidad de horas programadas entre los títulos provenientes del resto de Iberoamérica.

\section{TABLA 4. Los 10 títulos más vistos en la televisión abierta}

\begin{tabular}{|c|c|c|c|c|c|c|c|c|}
\hline \multicolumn{2}{|r|}{ Título } & \multirow{2}{*}{\begin{tabular}{|l} 
Canal \\
Telefe
\end{tabular}} & \multirow{2}{*}{$\begin{array}{c}\text { Productora } \\
\text { Casablanca and } \\
\text { RecordTV }\end{array}$} & \multirow{2}{*}{$\begin{array}{c}\text { Formato/género } \\
\text { Telenovela/Bíblica }\end{array}$} & \multirow{2}{*}{$\begin{array}{c}\begin{array}{c}\text { No. de } \\
\text { cap/ep (en } \\
\text { 2020) }\end{array} \\
115\end{array}$} & \multirow{2}{*}{$\begin{array}{c}\begin{array}{c}\text { Franja } \\
\text { horaria }\end{array} \\
\text { Prime } \\
\text { Time }\end{array}$} & \multirow{2}{*}{\begin{tabular}{|c|}
$\begin{array}{c}\text { Rating } \\
(\mathbf{\%})\end{array}$ \\
12,6
\end{tabular}} & \multirow{2}{*}{$\begin{array}{c}\begin{array}{c}\text { Share } \\
(\%)\end{array} \\
24,1\end{array}$} \\
\hline 1 & Jesús & & & & & & & \\
\hline 2 & Separadas & El Trece & Pol-ka & Comedia & 35 & $\begin{array}{c}\text { Prime } \\
\text { Time }\end{array}$ & 9,0 & 18,3 \\
\hline 3 & Acoso & Telefe & Globo & Miniserie/Drama & 8 & $\begin{array}{l}\text { Prime } \\
\text { Time }\end{array}$ & 6,9 & 17,4 \\
\hline 4 & $\begin{array}{l}\text { Los } \\
\text { internacionales }\end{array}$ & Telefe & Viacom Studios & Miniserie/Policial & 8 & Noche & 4,6 & 12,8 \\
\hline 5 & Club 57 & Telefe & $\begin{array}{l}\text { Rainbow SpA y } \\
\text { Nickelodeon }\end{array}$ & Telenovela/Musical & 60 & Mañana & 1,0 & 4,9 \\
\hline 6 & La promesa & Net TV & $\mathrm{CMO} /$ Caracol & Serie/drama & 67 & Tarde & 0,6 & 1,4 \\
\hline 7 & La persuasión & \begin{tabular}{|l} 
TV \\
Pública
\end{tabular} & El Buey solo & Miniserie/comedia & 8 & Noche & 0,5 & 2,2 \\
\hline 8 & Fugitivos & Net TV & Caracol & Serie/drama & 19 & Tarde & 0,5 & 1,3 \\
\hline 9 & $\begin{array}{l}\text { Terapia en } \\
\text { cuarentena }\end{array}$ & \begin{tabular}{|l} 
TV \\
Pública
\end{tabular} & $\begin{array}{l}\text { NOS/Contenidos } \\
\text { Públicos S.E }\end{array}$ & Miniserie/comedia & 8 & Noche & 0,3 & 1,2 \\
\hline 10 & Si solo si & \begin{tabular}{|l} 
TV \\
Pública
\end{tabular} & $\begin{array}{l}\text { Manda de Dos } \\
\text { Producciones }\end{array}$ & Miniserie & 24 & Mañana & 0,2 & 0,8 \\
\hline
\end{tabular}

Fuente: KantarIbope Media y Obitel Argentina 
Continúa la tendencia que se observa en los últimos años de caída en el promedio de rating y share de los diez títulos más vistos. Habitualmente el top ten que presenta Obitel Argentina muestra que Telefe y El Trece se reparten la participación en este listado casi en partes iguales, tanto con producciones nacionales o del ámbito Obitel. Sin embargo, 2020 es atípico ya que los dos canales líderes programaron un título nacional cada uno, tratándose en el caso de Telefe de una coproducción. Luego de haber recuperado el primer lugar para un título nacional en 2019, durante 2020 un título brasileño se impone nuevamente como la ficción de estreno más vista. De hecho, si fuera posible considerar a las ficciones de origen turco, el listado de las más vistas lo integrarían siete ficciones turcas, dos brasileñas y solo una argentina. Por la muy reducida emisión de títulos nacionales fue innecesaria la confección de la tabla que habitualmente se presenta aquí con los títulos argentinos más vistos, porque la anterior contiene casi la totalidad de los títulos estrenados incluyendo a todos los nacionales.

TABLA 5. Perfil de audiencia de los 10 títulos más vistos: género, edad, nivel socioeconómico.

\begin{tabular}{|c|l|l|c|c|c|c|c|c|}
\hline \multirow{2}{*}{\multicolumn{2}{|c|}{ Títulos }} & \multirow{2}{*}{ Canal } & \multicolumn{2}{c|}{ Género \% } & \multicolumn{3}{c|}{ Nível socioeconómico \% } \\
\cline { 4 - 10 } & & Mujeres & Hombres & ABC1 & C2 & C3 & D \\
\hline 1 & Jesús & Telefe & 55,0 & 45,0 & 1,6 & 15,5 & 38,6 & 44,3 \\
\hline 2 & Separadas & El Trece & 53,5 & 46,5 & 6,5 & 38,1 & 30,6 & 24,8 \\
\hline 3 & Acoso & Telefe & 62,7 & 37,3 & 6,4 & 27,1 & 30,5 & 36,0 \\
\hline 4 & Los internacionales & Telefe & 52,2 & 47,8 & 12,6 & 15,2 & 31,4 & 40,8 \\
\hline 5 & Club 57 & Telefe & 57,2 & & 0,8 & 19,4 & 22,8 & 57,0 \\
\hline 6 & La promesa & Net TV & 72,1 & 27,9 & 6,6 & 21,9 & 19,5 & 52,0 \\
\hline 7 & La persuasión & $\begin{array}{l}\text { TV } \\
\text { Pública }\end{array}$ & 32,5 & 67,5 & 0,0 & 60,6 & 23,1 & 16,3 \\
\hline 8 & Fugitivos & Net TV & 61,6 & 38,4 & 0,2 & 9,8 & 12,6 & 77,3 \\
\hline 9 & $\begin{array}{l}\text { Terapia en } \\
\text { cuarentena }\end{array}$ & $\begin{array}{l}\text { TV } \\
\text { Pública }\end{array}$ & 19,6 & 80,4 & 0,0 & 17,0 & 51,4 & 31,5 \\
\hline 10 & Si solo si & $\begin{array}{l}\text { TV } \\
\text { Pública }\end{array}$ & 37,5 & 62,5 & 4,2 & 26,3 & 52,6 & 16,9 \\
\hline
\end{tabular}




\begin{tabular}{|c|l|l|c|c|c|c|c|}
\hline \multirow{2}{*}{ Títulos } & \multirow{2}{*}{ Canal } & \multicolumn{5}{c|}{ Franjas de edad \% } \\
\cline { 4 - 8 } & & $\mathbf{4}$ a 12 & $\mathbf{1 3}$ a 18 & $\mathbf{1 9}$ a 24 & $\mathbf{3 5}$ a 44 & $\mathbf{4 5}+$ \\
\hline 1 & Jesús & Telefe & 18,4 & 23,2 & 24,1 & 17,1 & 17,3 \\
\hline 2 & Separadas & El Trece & 13,3 & 24,7 & 18,9 & 26,8 & 16,2 \\
\hline 3 & Acoso & Telefe & 14,6 & 19,0 & 28,6 & 17,0 & 20,8 \\
\hline 4 & Los internacionales & Telefe & 13,6 & 25,3 & 27,6 & 17,5 & 16,1 \\
\hline 5 & Club 57 & Telefe & 29,6 & 19,6 & 27,5 & 13,7 & 9,5 \\
\hline 6 & La promesa & Net TV & 11,2 & 11,6 & 41,4 & 10,8 & 25,1 \\
\hline 7 & La persuasión & TV Pública & 34,5 & 4,0 & 3,8 & 23,5 & 34,1 \\
\hline 8 & Fugitivos & Net TV & 26,9 & 22,8 & 19,2 & 7,0 & 24,0 \\
\hline 9 & Terapia en cuarentena & TV Pública & 3,8 & 0,0 & 0,0 & 27,9 & 68,3 \\
\hline 10 & Si solo si & TV Pública & 5,0 & 31,5 & 32,1 & 12,4 & 19,0 \\
\hline
\end{tabular}

Fuente: KantarIbope Media y Obitel Argentina

Medido por género este año la audiencia se reparte en promedio en partes prácticamente iguales entre mujeres $(50,4 \%)$ y hombres $(49,6 \%)$ lo que quizás se explique no tanto en cambios en el perfil de las ficciones programadas como en la mayor presencia de la familia en el hogar a lo largo del día, producto del confinamiento. En cuanto al nivel socioeconómico, se aceleró fuertemente la caída de audiencia de mayor poder adquisitivo que representó apenas el 3,9\% en promedio para las 10 primeras ficciones. Los sectores de clase media (C2 y C3) concentraron el 56,4\% de la audiencia, mientras que el 39,7\% restante lo completan quienes se encuentran en la base de la pirámide por nivel socioeconómico. Las audiencias con mayor capacidad de compra diversifican su dieta de consumos culturales en la creciente oferta de plataformas de video a demanda, mientras que la televisión abierta queda como un espacio para sectores medios y populares de menores ingresos. El 64,7\% de la audiencia de la ficción en TV de aire tiene 18 años o más, mientras que el público infanto-juvenil representa el 35,3\% restante, una caída de 3\% respecto del año anterior. En suma, pese a la excepcionalidad del año y las transformaciones en la domesticidad, la televisión abierta y en particular la ficción no logró revertir tendencias que reportamos desde hace varios años referidas a la paulatina pérdida 
de audiencia de la televisión abierta, junto al empobrecimiento y envejecimiento de las audiencias que consumen ficción en esa pantalla.

\section{Monitoreo VoD 2020}

A partir de marzo y luego de las primeras medidas de contención contra la pandemia de Covid-19 implementadas por el Gobierno Nacional, que incluyó un prolongado periodo de aislamiento social, la mayor permanencia de las personas en los hogares alteró los patrones habituales de la economía de la atención. Los datos disponibles muestran un mayor crecimiento en el número de suscriptores a las principales plataformas, junto a una mayor cantidad de horas dedicadas al visionado de contenidos a demanda. Las plataformas se beneficiaron del contexto global no solo por la mayor disponibilidad de tiempo y recursos para destinar al ocio doméstico, sino también por sus modelos de negocio independientes del mercado publicitario, en retracción a nivel global. A su vez, la mayor planificación en la producción de contenidos originales y el licenciamiento de contenidos producidos en distintos países les permitió, a diferencia de la televisión lineal, presentar novedades durante prácticamente todo el año. El adelantamiento de la llegada de Disney+ a la región es un hecho relevante para este mercado, pero aún no ingresa en el radar de nuestras observaciones en la medida que hasta el momento basa su oferta de contenidos en el extenso catálogo que lo antecede antes que en la producción de contenidos originales de ficción.

\subsection{Mercado de plataformas de VoD}

El 2020 fue un año de desembarco, expansión y crecimiento para varias de las principales plataformas de video a demanda que operan en el país. Netflix continúa como el actor principal de este mercado. Según datos de la consultora local Carrier y Asociados se estimaba que a mitad de 2020 había en el país 4,8 millones de abonados al ser- 
vicio de Netflix, lo que por las prácticas de compartición de cuentas y consumo familiar representa un número muy superior de espectadores reales. La cifra es significativa porque en medio de la pandemia, la plataforma logró atraer 800 mil nuevos suscriptores en comparación al año anterior, según la misma consultora. Si se considera el total de las importaciones de servicios audiovisuales realizados en 2020, el 65\% corresponden a Netflix, el $18 \%$ a Spotify y el 17\% a todas las demás plataformas que ofrecen servicios audiovisuales a demanda desde el exterior del país. Si se considera que hay en el país más de 7 millones de hogares con banda ancha, los servicios de VoD tendrían todavía un amplio margen para seguir creciendo, a diferencia de la situación que se verifica en mercados como Estados Unidos y Canadá ya próximos a la saturación. No obstante, en 2020 Netflix también empezó a sentir la mayor presión competitiva de otras grandes corporaciones que hicieron sus lanzamientos definitivos en la región (González, 2020). En particular Disney+ adelantó sus planes para América Latina con un catálogo amplio y familiar, con el que alcanzó casi 3,5 millones de descargas de su aplicativo entre octubre de 2020 y febrero de 2021, según estimaciones de Statista (2020)

Las plataformas estatales también crecieron el año de la pandemia, en particular Cine.ar Play, el VoD del Instituto Nacional de Cine (INCAA) que ofreció contenidos argentinos en modalidad gratuita y estrenos de cine nacional en modo de pago por transacción (TVOD). Según datos presentados por SInCA, la plataforma alcanzó los 514 mil usuarios activos en 2020, contra 250 mil del año anterior.

\subsection{Análisis del VoD en 2020: la ficción de estreno nacional e ibe- roamericana}

En 2019 Obitel Argentina había reportado el estreno en plataformas de 13 títulos de origen nacional, 39 de países de Iberoamérica y 2 coproducciones. En 2020, en cuanto a la producción nacional la cifra de estrenos no varió significativamente en relación al año ante- 
rior, aunque sí se observa un incremento en el número de títulos provenientes del ámbito Obitel, en especial gracias a la mayor incorporación de contenidos al catálogo de Prime Video, que pasó de 3 a 17 títulos iberoamericanos en un año. En el mismo sentido la plataforma Movistar+ creció desde los 4 títulos que ofreció en 2019 hasta los 10 que incluyó en 2020. Con la excepción de Netflix que mantuvo en 24 el número ofertado en la comparación interanual, las plataformas incrementaron notablemente su oferta de contenidos en español. El hecho puede explicarse en la búsqueda por capturar cuotas de mercado en un contexto de pandemia en que las audiencias dedicaron más tiempo al consumo de contenidos a demanda y crecieron las suscripciones a este tipo de servicios.

\begin{tabular}{|c|c|c|}
\hline $\begin{array}{l}\text { TÍTULOS } \\
\text { NACIONALES DE } \\
\text { ESTRENO }\end{array}$ & $\begin{array}{l}\text { TÍTULOS } \\
\text { IBEROAMERICANOS DE } \\
\text { EXTRENO }\end{array}$ & COPRODUCCIONES \\
\hline $\begin{array}{l}\text { Cablevisión FLOW - } 5 \\
\text { títulos nacionales } \\
\text { 1. Tony (miniserie) } \\
\text { 2. Adentro (miniserie) } \\
\text { 3. Pepper, todo por un like } \\
\text { (miniserie) } \\
\text { 4. Post Mortem (miniserie) } \\
\text { 5. Famoso (miniserie) } \\
\text { Netflix - } \mathbf{3} \text { títulos } \\
\text { nacionales } \\
\text { 6. Puerta } 7 \text { (miniserie) } \\
\text { 7. Casi Feliz (miniserie) } \\
\text { 8. Secreto bien guardado } \\
\text { (miniserie) } \\
\text { Cont.ar - } 3 \text { títulos } \\
\text { nacional } \\
\text { 9. Terapia en cuarentena } \\
\text { (miniserie) } \\
\text { 10. No grites (miniserie) } \\
\text { 11. La Persuasión } \\
\text { (miniserie) }\end{array}$ & $\begin{array}{l}\text { Netflix - } \mathbf{2 4} \text { títulos } \\
\text { iberoamericanos } \\
\text { 1. La Casa de las Flores } 3 \\
\text { (serie - México) } \\
\text { 2. Control Z (serie - México) } \\
\text { 3. Diablero (serie - México) } \\
\text { 4. Oscuro Deseo (serie - } \\
\text { México) } \\
\text { 5. Historia de un crimen. La } \\
\text { búsqueda (serie - México) } \\
\text { 6. Desenfrenadas (serie - } \\
\text { México) } \\
\text { 7. Onisciente (serie - Brasil) } \\
\text { 8. Spectros (serie - Brasil) } \\
\text { 9. Reality Z (serie - Brasil) } \\
\text { 10. Boca a Boca (serie - } \\
\text { Brasil) } \\
\text { 11. Coisa Mais Linda (serie } \\
\text { - Brasil) } \\
\text { 12. 3 \% (serie - Brasil) } \\
\text { 13. Bom dia, Verônica (serie } \\
\text { - Brasil) } \\
\text { 14. El robo del siglo (serie - } \\
\text { Colombia) } \\
\text { 15. La venganza de Analia } \\
\text { (serie - Colombia) }\end{array}$ & $\begin{array}{l}\text { Prime Video - } 1 \text { título } \\
\text { 1. El Presidente (miniserie } \\
\text { - Argentina, Chile) } \\
\text { Cablevisión Flow - } \mathbf{1} \\
\quad \text { título } \\
\text { 2. Los Internacionales } \\
\text { (miniserie - Argentina, } \\
\text { Colombia) }\end{array}$ \\
\hline
\end{tabular}




\begin{tabular}{|c|c|c|}
\hline $\begin{array}{l}\text { TÍTULOS } \\
\text { NACIONALES DE } \\
\text { ESTRENO }\end{array}$ & $\begin{array}{l}\text { TÍTULOS } \\
\text { IBEROAMERICANOS } \\
\text { DE EXTRENO }\end{array}$ & COPRODUCCIONES \\
\hline $\begin{array}{l}\text { Movistar Play - } 1 \text { título } \\
\text { nacional } \\
\text { 12. Manual de } \\
\text { Supervivencia (miniserie) }\end{array}$ & $\begin{array}{l}\text { 16. Amar y Vivir (serie - } \\
\text { Colombia) } \\
\text { 17. Alguien tiene que morir } \\
\text { (miniserie - España) } \\
\text { 18. El desorden que dejas } \\
\text { (miniserie - España) } \\
\text { 19. Élite (serie - España) } \\
\text { 20. Las chicas del cable } \\
\text { (serie - España) } \\
\text { 21. Los favoritos de Midas } \\
\text { (serie - España) } \\
\text { 22. El sabor de las } \\
\text { margaritas (serie - } \\
\text { España) } \\
\text { 23. Valeria (serie - España) } \\
\text { 24. Vivir sin permiso (serie } \\
\text { - España) } \\
\text { Amazon Prime - 17 } \\
\text { títulos iberoamericanos } \\
\text { 25. De brutas nada (serie - } \\
\text { México) } \\
\text { 26. Cómo sobrevivir soltero } \\
\text { (serie - México) } \\
\text { 27. Pan y Circo (serie - } \\
\text { México) } \\
\text { 28. El Candidato (serie - } \\
\text { México) } \\
\text { 29. Home Office (unitario - } \\
\text { México) } \\
\text { 30. Homens? (serie - } \\
\text { Brasil) } \\
\text { 31. Impuros (serie - Brasil) } \\
\text { 32. Sonhadores (serie - } \\
\text { Brasil) } \\
\text { España) } \\
\text { 33. Me Chama de Bruna } \\
\text { (serie - Brasil) } \\
\text { 34. Brantra Todos (serie } \\
\text { 35. Dignidade (serie - } \\
\text { Esie - }\end{array}$ & \\
\hline
\end{tabular}




\begin{tabular}{|c|c|c|}
\hline $\begin{array}{l}\text { TÍTULOS } \\
\text { NACIONALES DE } \\
\text { ESTRENO }\end{array}$ & $\begin{array}{l}\text { TÍTULOS } \\
\text { IBEROAMERICANOS } \\
\text { DE EXTRENO }\end{array}$ & COPRODUCCIONES \\
\hline & $\begin{array}{l}\text { 37. Desaparecidos (serie - } \\
\text { España) } \\
\text { 38. El cid (miniserie - } \\
\text { España) } \\
\text { 39. Inés del alma mía } \\
\text { (serie - España, Chile) } \\
\text { 40. Madres (serie - } \\
\text { España) } \\
\text { 41. El pueblo (serie - } \\
\text { España) } \\
\text { Movistar+- 10 títulos } \\
\text { iberoamericanos } \\
\text { 42. Antidistubios (serie - } \\
\text { España) } \\
\text { 43. El embarcadero (serie } \\
\text { - España) } \\
\text { 44. Justo antes de Cristo } \\
\text { (serie - España) } \\
\text { 45. La línea invisible (serie } \\
\text { - España) } \\
\text { 46. La unidad (serie - } \\
\text { España) } \\
\text { 47. Mira lo que has hecho } \\
\text { (serie - España) } \\
\text { 48. Nasdrovia (serie - } \\
\text { España) } \\
\text { 49. Skam (serie - España) } \\
\text { 50. Vergüenza (serie - } \\
\text { España) } \\
\text { 51. Dime quién soy (serie - } \\
\text { España) } \\
\text { Claro Video - 5 títulos } \\
\text { iberoamericanos } \\
\text { 52. DesHecho en casa } \\
\text { (serie - México) } \\
\text { 53. Orgullo México (serie } \\
\text { - México) } \\
\text { 54. Herederos por } \\
\text { Accidente (serie - México) } \\
\text { 55. Promesas de Campaña } \\
\text { (serie - México) } \\
\text { 56. Manual para Galanes } \\
\text { (serie - México) }\end{array}$ & \\
\hline Total: 12 & Total: 56 & Total: 2 \\
\hline \multicolumn{2}{|c|}{ TOTAL GENERAL: 70} & Fuente: Obitel Argentina \\
\hline
\end{tabular}


Tabla 6. Ficciones nacionales e iberoamericanas exhibidas en 2020 en sistemas de VoD

Cablevisión Flow (Grupo Clarín) funciona como un espacio de distribución de contenidos de los propios canales del Grupo que integra, pero fundamentalmente de señales de TV pago, otros canales de aire y de contenidos exclusivos ya sea licenciados o de producción original. En 2020 se consolidó una tendencia que ya habíamos reportado el año anterior referida al licenciamiento de webseries producidas en el ámbito universitario, en particular desde la Universidad de Tres de Febrero (Buenos Aires). Flow ya ha incorporado al menos una docena de webseries producidas por la casa de estudios dentro de su catálogo.

Tabla 7. La ficción de estreno en 2020 en VoD: países de origen

\begin{tabular}{|l|c|c|}
\hline \multicolumn{1}{|c|}{ País } & Títulos & $\mathbf{\%}$ \\
\hline NACIONAL (total) & $\mathbf{1 2}$ & $\mathbf{1 7 , 2}$ \\
\hline PAÍSES OBITEL (total) & $\mathbf{5 5}$ & $\mathbf{7 8 , 5}$ \\
\hline Argentina & 12 & 17,1 \\
\hline Brasil & 13 & 18,5 \\
\hline Chile & 1 & 1,4 \\
\hline Colombia & 3 & 4,2 \\
\hline España & 23 & 32,8 \\
\hline EE.UU. (producción hispánica) & 0 & 0,0 \\
\hline México & 16 & 22,8 \\
\hline Perú & 0 & 0,0 \\
\hline Portugal & 0 & 0,0 \\
\hline Uruguay & 0 & 0,0 \\
\hline Venezuela & 0 & 0,0 \\
\hline COPRODUCCIONES (total) & $\mathbf{3}$ & $\mathbf{4 , 3}$ \\
\hline Coproducciones argentinas & $\mathbf{2}$ & 0,0 \\
\hline $\begin{array}{l}\text { Coproducciones entre países } \\
\text { OBITEL }\end{array}$ & $\mathbf{1}$ & 0,0 \\
\hline TOTAL GENERAL & $\mathbf{5 4}$ & $\mathbf{1 0 0 , 0}$ \\
\hline
\end{tabular}


En las plataformas de VoD observadas se impone la ficción de países del ámbito Obitel, en especial España, México y Brasil donde tanto Netflix como otros servicios globales mantienen desde hace algunos años una política intensa de producción de contenidos locales. Argentina llega rezagada en la medida que son todavía escasos los títulos locales generados por servicios internacionales. Al cierre de este capítulo la plataforma global tenía en etapa de producción la segunda temporada de la serie original Casi Feliz y una nueva producción, El Reino, ambas con fecha de estreno para 2021.

\section{Ficción y participación de las audiencias en entornos digitales}

\subsection{Propuestas de expansión digital}

La ya reportada caída de la audiencia de televisión abierta no supone una ausencia de consumo de ficción seriada, las plataformas de streaming fueron las grandes ganadoras durante la pandemia (ver más arriba). Si bien no contamos aun con datos que cuantifiquen la cantidad de espectadores que pasaron de la pantalla del televisor a otras formas de visionado, en Argentina la llegada de empresas de streaming ha crecido, a ellas se suman otras plataformas estatales y nuevas propuestas más curadas como Retina Latina -audiovisual latinoamericano-, Mubi -disponibiliza por un plazo de treinta días una película por día con un criterio curatorial explicitado-, Qubit -según su propia descripción "el mejor cine del mundo seleccionado por expertos"-, entre otras plataformas. A ellas se suman espacios que las propias señales o series habilitan para visionado de sus producciones (YouTube, Facebook, Instagram, etc.). Las plataformas de streaming y video on demand han expandido tanto los contenidos que tradicionalmente se miraban a través de la televisión de pago, sino también han ampliado la posibilidad de visionado a demanda de las producciones estrenadas en las pantallas televisivas. Este es el caso de Cont.ar la plataforma de streaming estatal que opera en paralelo con la Televisión Pública, pero también 
funciona como repositorio digital a la vez que cuenta con una señal en la televisión de pago. De este modo, la proliferación de posibilidades de visionado de una misma ficción nacional se multiplica por lo menos por tres, sin contar las estrategias de reposición en sitios web de los mismos canales de televisión, sus canales de YouTube, etc.

En 2020, El Trece destina un espacio en su página web para visionado de los 36 capítulos de Separadas, pero no ofrece más que los capítulos, los que también pueden encontrarse en YouTube. En Instagram, la tira comunicó especialmente fotos de los actores y actrices previas al estreno y luego imágenes de los personajes en momentos de la ficción y fuera de ellas. En esta red, se anunció de manera ficcional, pero anclada en el contexto sanitario de la Pandemia de la Covid-19 el cierre de la ficción misma, como el cierre del bar que formaba parte de la trama.

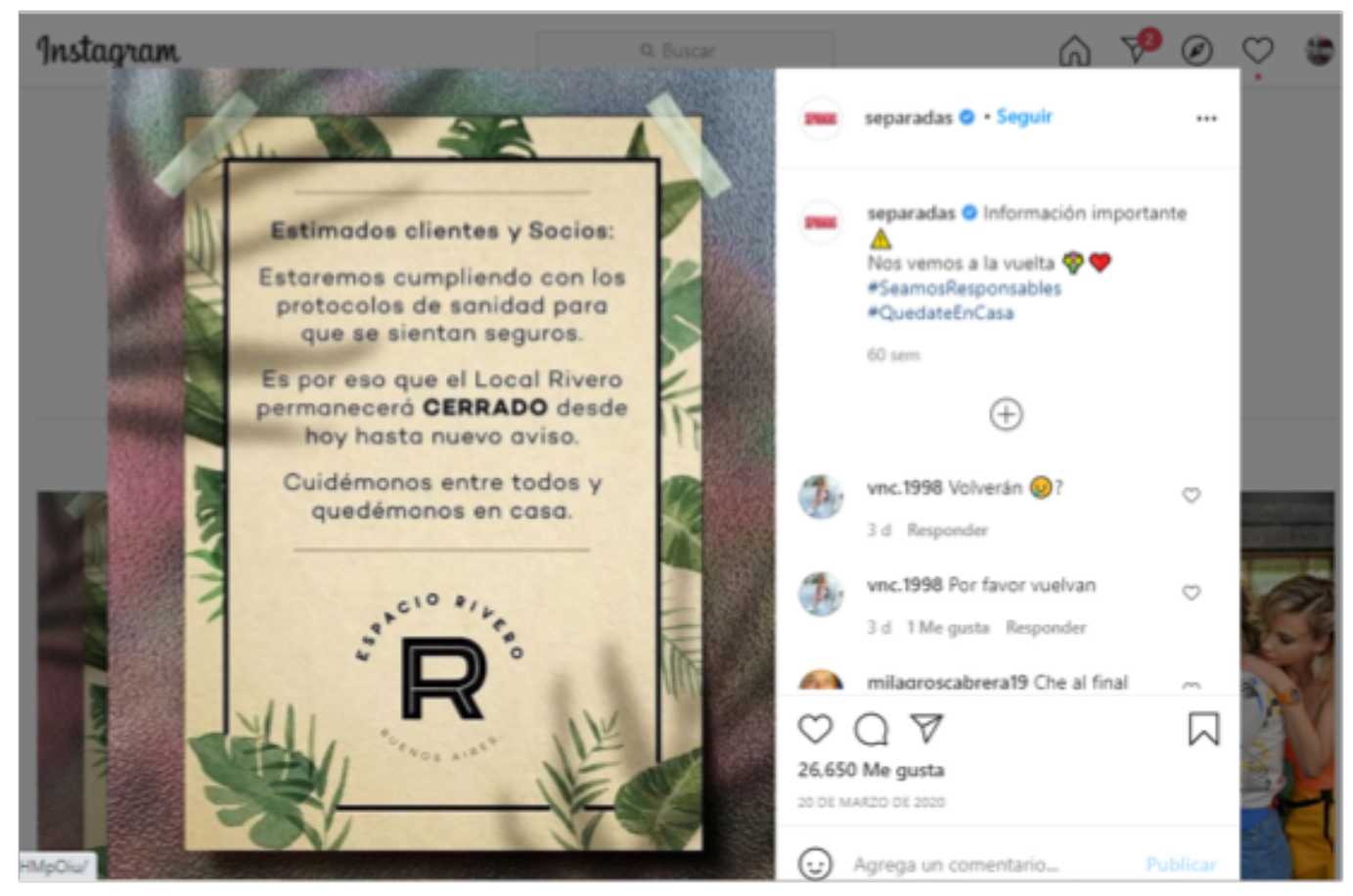

Por su parte, es interesante el caso de la tercera temporada de Si solo si (TV Pública), una serie de ficción que incluye entre sus protagonistas a actores con discapacidades, y cuenta con un sitio web 
propio, ya que su llegada a la televisión abierta es posterior a otras iniciativas. "Si solo si es un concepto integrado que se inicia en el año 2012 con una serie web y comienza a evolucionar hasta convertirse en lo que es hoy... una marca que trasciende la televisión y se desarrolla también en otras plataformas. Los diferentes productos en donde se refleja el concepto de Si solo Si son, sin lugar a dudas, de una nobleza y una perseverancia que trasciende el trabajo individual de su creador, Sebastián Suárez. El trabajo en equipo, el profesionalismo y por sobre todas las cosas la pasión hacen de Si solo Si lo que es hoy y lo que será con el paso del tiempo, ya que el concepto se encuentra en constante evolución. En ella se pone de manifiesto la idea de televisión integrada, que se destaca por ser el proyecto que dio el puntapié inicial para acercar la inclusión de personas con discapacidad al público de manera masiva; ya que es la primera serie de ficción en la historia de la televisión mundial que integra en su elenco actores con y sin discapacidad." Así, Si solo si está presente en todas las redes sociales, en plataformas del estado como Cont.ar y como se reportó fue estrenada en la pantalla de la Televisión Pública. En estos espacios se excede la temática de la ficción, allí se difunde información en torno de las temáticas de diversas discapacidades, en Instagram se hicieron distintos "vivos" con actores de la serie, así como se informan avances, promociones e imágenes de los capítulos y de la producción. En su sitio web cuentan también con contenidos exclusivos como "cocina" donde se presentan videos donde se enseñan recetas, se ofrece un cine móvil para escuelas, se informa de un documental en preparación, un libro en torno de las temáticas de la discapacidad realizado en conjunto con el Instituto Nacional contra la Discriminación, la Xenofobia y el Racismo (INADI).

De todas las propuestas de transmedialidad, la de Si solo si se vuelve la más interesante, dado que no solo comparte su programación en segundas pantallas, sino que desde estos espacios puede convocar 
espectadores, más allá de las pantallas, ofreciendo contenidos más allá de la propia ficción.

\section{Lo Más Destacado del Año}

A lo largo del 2020, lo más destacado del año fue el cambio de peso relativo de oferta de la televisión abierta. Si bien, como se reporta en los apartados anteriores, la ficción mantuvo un espacio en la pantalla televisiva (30 reposiciones en 2020, frente a las 3 del 2019), la producción de ficción nacional se detuvo. Ello permitió un reingreso de otros géneros como el magazine y los programas de entretenimiento. El contexto de Aislamiento Social Preventivo y Obligatorio primero y de Distanciamiento Social luego, supuso también una mayor demanda de información, y de esta manera un mayor encendido televisivo. Como puede verse en el reporte de las diez ficciones más vistas, no fue la ficción de estreno lo que convocó a esa audiencia que retornó; antes bien recibieron el favor de la audiencia los programas de entretenimiento y de concursos En El trece vuelve 100 Argentinos dicen, crece en horas tanto Corte y confección como El gran premio de la Cocina.

Por su parte, Telefe celebró su $30^{\circ}$ aniversario con una estrategia exitosa (y muy acorde al contexto), repuso en su pantalla muchas de las ficciones míticas de su historia. Se trató de un segmento denominado 30 años juntos, en este espacio se emitieron capítulos de Casi Ángeles, Educando a Nina, Los Roldán, Atreverse. También fueron parte del autohomenaje las ficciones extranjeras como Avenida Brasil, ¿Qué culpa tiene Fatmagul? o Moisés y los 10 mandamientos. De este modo, la pantalla se pobló de narrativas familiares y nostalgia.

Si observamos la distribución de horas por género, podemos ver que la cantidad de horas destinadas a la información en general se impone sobre los demás géneros, así como el lugar destacado del entretenimiento. 


\section{Gráfico 4. Cantidad de horas emitidas por género}

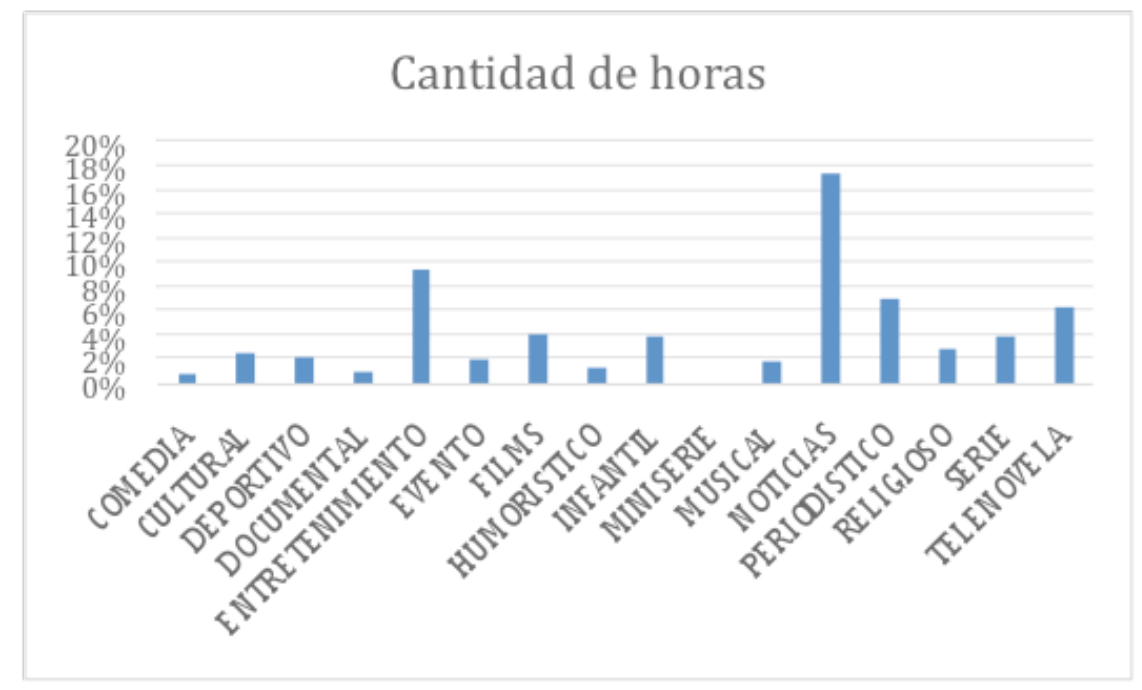

Fuente: Kantar Ibope Media y Obitel Argentina

$\mathrm{Si}$, en cambio, atendemos al rating por género vemos que se mantiene el espacio de las ficciones en la preferencia del público, junto al mayor interés por la información. Un dato relevante, que permite ver una posible reconversión de la oferta de televisión abierta es la mayor preponderancia de los programas de entretenimiento con un rendimiento aceptable. El Trece, por ejemplo, programó este género en el horario vespertino durante todo el año.

\section{Gráfico 5. Rating hogares por género}

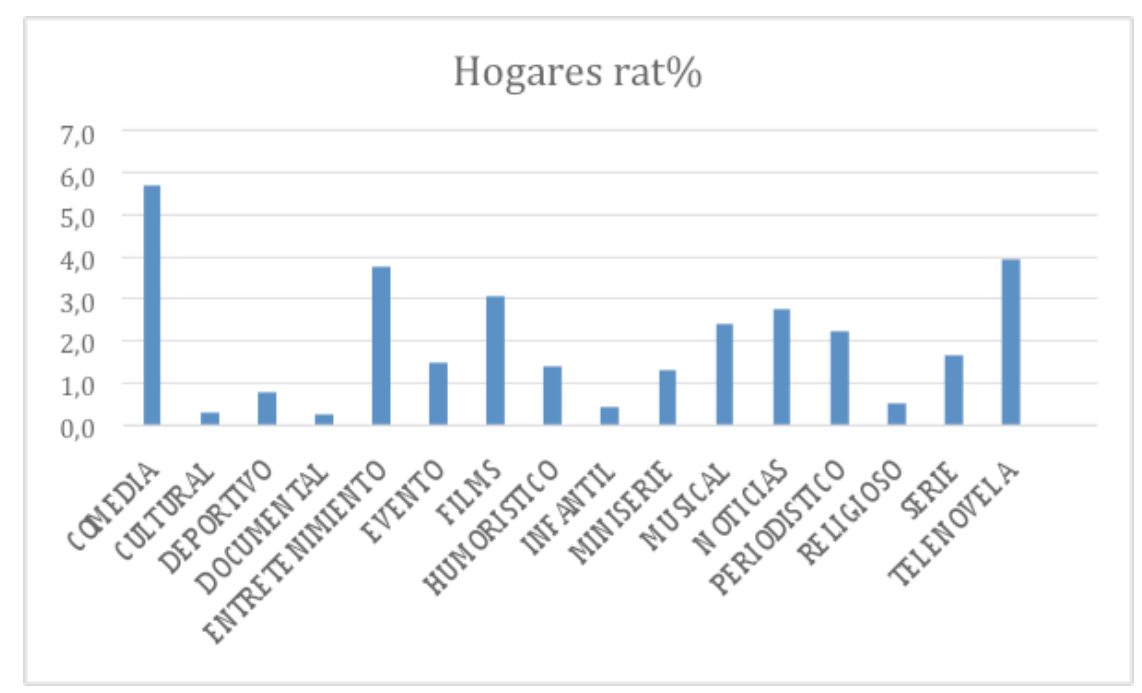

Fuente: Kantar Ibope Media y Obitel Argentina 
En cuanto a la ficción de estreno, interesa destacar que fue en el espacio de la Televisión Pública que se programaron cuatro de las cinco ficciones de estreno. Ellas contaron con una variedad temática importante, como es el caso de la ya mencionada tercera temporada de Si solo si pone en evidencia que la discapacidades no hace sujetos inhábiles; La persuasión trabaja de la mano de una ficción paranoica, una crítica al tratamiento y uso mediático de la información; Terapia en cuarentena, por su parte, tematiza mientras sucede, la situación de cuarentena a partir de la ficción ya conocida de las sesiones de terapia; finalmente, Separadas se trató de una ficción coral, en la que sietes mujeres son víctimas de un fraude inmobiliario. Es interesante el rol de la Televisión Pública ya que eligió programar ficciones de estreno con contenido que va más allá del espacio de la ficción y claro peso del merchandising social; no obstante, y como suele ocurrir, los espacios en los que estas ficciones se programaron no logran llamar la atención de la audiencia, por los habituales bajos niveles de audiencia del canal estatal.

\section{El Tema del Año: La Ficción en tiempos de pandemia en Argentina}

Como fuera señalado en apartados anteriores, durante el 2020 la producción argentina de ficción se paró completamente. En el mes de marzo se dispone el Aislamiento Social Preventivo y Obligatorio. A pesar de que el cambio de Aislamiento a Distanciamiento se produce recién en el mes de noviembre, a lo largo del año se fueron incorporando con protocolos diversas actividades. Hasta el mes de agosto estuvieron suspendidas todas las actividades presenciales no definidas como esenciales. En este marco comienzan a aprobarse diversos protocolos y recomendaciones de buenas prácticas en el marco de la pandemia de la Covid-19. 
En este contexto, para el mes de abril -un mes después del primer anuncio de ASPO-, la apuesta más importante de El Trece, Separadas, anuncia su suspensión y más tarde su levantamiento. Entendemos que esta total parálisis es inédita desde el inicio de la televisión abierta en Argentina.

Con el correr de los meses y las decisiones de programar ficción extranjera muchas agrupaciones de actores reclamaron que los canales de televisión abierta repusieran ficciones nacionales de manera de cobrar por los derechos de interprete, dado que el sector se desmoronó de manera abrupta. Esta crisis también llegó a las productoras, el caso más notable es el de la productora asociada a El Trece, Pol-Ka que en julio anunciaba una crisis terminal y el cierre de sus puertas, tuvo que despedir a fin de año cerca del cincuenta por ciento de sus empleados (140 despidos). De este modo evitó la quiebra la productora que hasta hace cinco años estrenaba en la pantalla de El Trece dos tiras diarias anuales y un unitario semestral.

También de manera extraordinaria se detuvo la exhibición de films en salas cinematográficas y de espectáculos en vivo. En este contexto, muchos actores y actrices se volcaron a la producción de espectáculos por streaming y desde sus propios domicilios, ya sea reponiendo teatro filmado, como ideando nuevas formas de producción para ello. Un caso extremo fueron las experiencias de teatro telefónico, en el que los receptores recibieron en sus celulares a lo largo de varios días audios de la obra.

La posibilidad de producir ficción con el protocolo correspondiente se eleva al Poder Ejecutivo en el mes de agosto, por parte del Ministerio de Cultura de la Nación y el finalmente autorizada. En él se establecen parámetros que vuelven casi inviable la producción audiovisual. Además de las recomendaciones sanitarias, el escalonamiento de tareas que permitan convocar a la menor cantidad de personas posibles para el rodaje, las recomendaciones de información y sanitarias preventivas generales, los controles de temperatura e hisopados se 
establece que "Las Empresas tomarán todas las medidas preventivas que sean posibles para que en todos los libros y/o formatos se procure mantener la distancia entre los miembros del Equipo Artístico/Extras/ participantes así como del Equipo Técnico y se minimice el contacto entre los mismos, siguiendo para cada caso las indicaciones publicadas por las autoridades sanitarias competentes y del Plan de Prevención de Riesgos Laborales propio de cada producción." (2020: 28-9) En este sentido no es posible realizar grabaciones en locación, ya que la trama hace que los actores deban estar a una distancia de menos de los 2 metros recomendados.

A pesar de estas restricciones una ficción pandémica se destaca. Se trata de Terapia en Cuarentena, estrenada en agosto. De acuerdo con Emanuel Respighi, la serie presenta a "Rosario (Mercedes Funes) es una madre que no puede resolver -mucho menos disfrutar- su maternidad en cuarentena. Julio (Coco Sily) es un sesentón que se instaló en la casa de su mamá para poder cuidarla y sufre la convivencia hasta la asfixia. Malena (Violeta Urtizberea) es una médica que interviene en la pandemia y a la que los vecinos del edificio donde vive la quieren linchar por miedo a que los contagie. Diego (Luciano Cáceres) es un gay que no soporta el encierro, la imposibilidad de ir al gimnasio y la inactiva vida sexual que le impone la pandemia. Todos padecen el aislamiento social preventivo obligatorio, pero no se conocen entre sí. Sólo comparten a la misma terapeuta, Anita (Carola Reyna), que trata de ayudarlos a resolver sus problemas a través de sesiones online. Ese es el cuadro de relaciones de Terapia en cuarentena, la única ficción que pudo grabarse en el país desde que se decretó la emergencia sanitaria" (2021)

En la nota, Respighi destaca que "Fueron las mismas actrices y los mismos actores quienes se grabaron a sí mismos, pero asistidos y dirigidos de manera remota por el equipo creativo de la productora NOS. Para ello, cada uno de los integrantes del elenco recibieron -por mensajería- un teléfono celular inteligente y un equipo básico de 
cámara y fotografía, además de elementos de prevención y seguridad (como barbijos, alcohol en gel, guantes). Todo ese material grabado remotamente, finalmente fue editado por el equipo de posproducción de la productora, con cada uno de los técnicos involucrados también desde sus hogares." (2021)

Un aspecto interesante de la única ficción Argentina filmada en pandemia sobre la pandemia es que la variedad de situaciones en las que se encuentran los personajes permite la entrada de las diversas problemáticas y sensaciones provocadas por el aislamiento, tanto de quien está enfrentando la situación sanitaria como de quienes conviven con personas de riesgo, ven alterada su vida cotidiana y sus rutinas. Estas tramas se desarrollan además a través de una puesta de cámara muy interesante. La situación de la cámara de computadora o de celular permite que la imagen "se caiga", "se congele", "se pixele", volviendo el propio dispositivo de la terapia un interesante espacio de experimentación audiovisual. La inhabitual interrupción de las sesiones se vuelve así uno de los leitmotiv de la serie, que pone en muchas ocasiones un tono de humor a una situación angustiante. Este tramitar el encierro que presenta Terapia en Cuarentena en tanto que ficción interpela extraordinariamente a su audiencia en simultáneo con sus propias experiencias. 


\section{Referencias}

Bulloni Yaquinta, M., et al. (2021). Impacto de la pandemia de la COVID-19 en el sector audiovisual y del espectáculo en vivo en las américas. Un estudio en ocho países. Buenos Aires, UMET

Espada, A. (2020, abril 12) En plena pandemia, la televisión se viraliza. Tiempo Argentino. https://www.tiempoar.com.ar/nota/en-plenapandemiala-television-se-viraliza

González, L. (2020) La pandemia disparó la curva del streaming. Tiempo Argentino. 28/06/2020. https://www.tiempoar.com.ar/nota/ la-pandemia-disparo-la-curva-del-streaming

INCAA (2020) Estadísticas del Instituto de Cine y Artes Audiovisuales. Disponibles en http://fiscalizacion.incaa.gov.ar/index_estadisticas.php

Nicolosi, A. (2021). Pandemia, ficción seriada y TV Pública: toda oferta es política. https:/www.agenciapacourondo.com.ar/cultura/ pandemia-ficcion-seriada-y-tv-publica-toda-oferta-es-politica

Parrot Analytics (2020) Navigating COVID-19. Special Report. Practical Solutions for Thriving in an Altered Attention Economy

Respighi, E. (2021, mayo 16) "La serie "Terapia en cuarentena" se estrena por Cont.ar" en Diario Página/12. https://www.pagina12. com.ar/265687-la-serie-terapia-en-cuarentena-se-estrena-porcont-ar

SInCA (2020). Impacto del COVID-19 en las industrias culturales. Dirección de planificación y seguimiento de gestión, Ministerio de Cultura de la Nación.

Statista (2020) Disney+ conquista Latinoamérica. Statista.com 17/02/2021 https://es.statista.com/grafico/23686/paises-conmas-descargas-de-la-app-de-disney-/ 
